\title{
Previous Stress Facilitates Fear Memory, Attenuates GABAergic Inhibition, and Increases Synaptic Plasticity in the Rat Basolateral Amygdala
}

\author{
Pablo A. Rodríguez Manzanares, ${ }^{1}$ Nora A. Isoardi, ${ }^{1}$ Hugo F. Carrer,${ }^{2}$ and Víctor A. Molina ${ }^{1}$ \\ ${ }^{1}$ Departamento de Farmacología, Facultad de Ciencias Químicas, Universidad Nacional de Córdoba, and ${ }^{2}$ Instituto de Investigación Médica Mercedes y \\ Martín Ferreyra, Consejo Nacional de Investigaciones Científicas y Técnicas, 5016 Córdoba, Argentina
}

In experiments designed to investigate the relationship between stress and the acquisition of new fear memories, it was found that previous exposure to a restraint session increased fear conditioning in a contextual fear paradigm. Moreover, the infusion of bicuculline, a competitive antagonist of $\mathrm{GABA}_{\mathrm{A}}$ receptors, into the basolateral amygdala complex (BLA), but not into the central amygdaloid nucleus, induced the same behavioral effect. Pretreatment with midazolam $(\mathrm{MDZ})$, a positive modulator of $\mathrm{GABA}_{\mathrm{A}}$ sites, prevented the facilitating influence on fear memory of both stress and $\mathrm{GABA}_{\mathrm{A}}$ receptor blockade in the BLA. These data suggest that facilitation of fear conditioning could be causally related to increased neuronal excitability attributable to depressed GABAergic inhibition in the BLA. To test this hypothesis, evoked potentials were studied in brain slices from stressed animals. Potentials evoked in the BLA by single stimuli applied to the external capsule showed multispike responses, suggestive of GABAergic disinhibition. These multiple responses were no longer evident after the slices were perfused with diazepam or if the stressed animals were pretreated with MDZ. In slices from stressed rats, paired-pulse inhibition (GABA dependent) was suppressed. Also, in stressed animals, long-term potentiation (LTP) was induced with a single train of high-frequency stimulation, which did not induce LTP in control rats. Moreover, MDZ pretreatment prevented the facilitating influence of stress on LTP induction. All of these findings support the hypothesis that previous stress attenuates inhibitory GABAergic control in the BLA, leading to neuronal hyperexcitability and increased plasticity that facilitates fear learning.

Key words: stress; fear memory; basolateral amygdala; GABAergic disinhibition; midazolam; LTP

\section{Introduction}

Previous exposure to both acute and chronic stressful events can positively affect classical conditioning tasks, including fear conditioning (Shors et al., 1992; Beylin and Shors, 1998; Shors, 2001; Cordero et al., 2003). Extensive evidence indicates that GABA transmission plays a primary role in the modulation of behavioral sequelae resulting from stress (Millan, 2003). Pharmacological studies support this view, because drugs acting on the $\mathrm{GABA}_{\mathrm{A}}$ receptor complex have a critical influence on behavioral responses to environmental challenges (Petersen et al., 1985; Biggio et al., 1990; Fanselow and Kim, 1992; Cancela et al., 1995; Cole et al., 1995; Jasnow and Huhman, 2001; Maren, 2001). Together, these studies suggest a functional association between changes in the activation of $\mathrm{GABA}_{\mathrm{A}}$ sites in selected corticolimbic areas and the occurrence of fear and anxiety. One candidate structure that

\footnotetext{
Received Dec. 20, 2004; revised July 20, 2005; accepted July 20, 2005.

This work was supported by grants from Agencia Córdoba Ciencia Sociedad del Estado and Consejo Nacional de Investigaciones Científicas y Técnicas to H.F.C. and V.A.M. and Secretaria de Ciencia y Tecnologia, Universidad Nacional de Còrdoba, and Agencia Nacional de Promoción Científica y Tecnológica (Argentina) to V.A.M. We gratefully acknowledge the technical assistance provided by Estela Salde and Dr. Carlos Mas.

Correspondence should be addressed to Víctor A. Molina, Facultad de Ciencias Químicas, Universidad Nacional de Córdoba, Departamento de Farmacología, Haya de la Torre y Medina Allende, Ciudad Universitaria Córdoba, 5016 Córdoba, Argentina. E-mail: vmolina@fcq.unc.edu.ar.

D0I:10.1523/JNEUROSCI.2260-05.2005

Copyright $\odot 2005$ Society for Neuroscience $\quad$ 0270-6474/05/258725-10\$15.00/0
}

could be a substrate for such function is the amygdala (Ledoux, 1993; Maren, 2001; McGaugh et al., 2002). A substantial number of studies have demonstrated that the basolateral complex of the amygdala (BLA) contains a powerful inhibitory circuit that uses GABA as a neurotransmitter (Takagi and Yamamato, 1981; Washburn and Moises, 1992a,b). Moreover, the BLA has larger amounts of benzodiazepine/GABA $\mathrm{A}$ receptors than any other amygdala nucleus (Niehoff and Kuhar, 1983), explaining why the infusion of benzodiazepines or $\mathrm{GABA}_{\mathrm{A}}$ agonists in the BLA reduced fear conditioning and anxiety (Scheel-Kruger and Petersen, 1982; Petersen et al., 1985; Muller et al., 1997; Jasnow and Huhman, 2001). Coincidentally, local blockade of these receptors attenuates the anxiolytic influence of systemic benzodiazepines (Sanders and Shekhar, 1991). In addition, decreased chloride uptake mediated by the $\mathrm{GABA}_{\mathrm{A}}$ receptor complex in this particular brain region appears to be one important effect of stress (Martijena et al., 2002). Based on these data, it can be concluded that GABAergic neurotransmission in the amygdala plays a major role in the control of the emotional consequences of stress. As a logical extension of this idea, we can hypothesize that changes in this system are involved in the stress-induced influence on the formation of new fear memories.

To explore this possibility, we evaluated the influence of a single exposure to a stressor (restraint) on subsequent pavlovian conditioning using a contextual fear paradigm. To test whether 
alterations of GABA transmission could explain the observed changes, we infused bicuculline methiodide (BMI) either into the BLA or into the central amygdaloid nucleus (CeA) and later tested the animals in the contextual fear-conditioning paradigm. On the same rationale, we tested the effect of pretreatment with midazolam (MDZ), before both restraint and BMI infusions.

To study whether previous stress exposure affects BLA synaptic transmission, we examined the potentials evoked in the BLA in slices obtained from control and previously restrained animals, with or without MDZ pretreatment. Based on the fact that fear conditioning produces changes in synaptic plasticity in the amygdala (Blair et al., 2001), we also evaluated whether previous restraint affects the induction of long-term potentiation (LTP) in the BLA.

\section{Materials and Methods}

Animals. Adult male Wistar rats (average weight, $290 \mathrm{~g}$ ) were housed in standard laboratory Plexiglas cages (four to five per cage) with food and water ad libitum. Animals were maintained throughout the experiments on a $12 \mathrm{~h} \mathrm{light/dark} \mathrm{cycle} \mathrm{(lights} \mathrm{on} \mathrm{at} \mathrm{7:00} \mathrm{A.M.)} \mathrm{with} \mathrm{a} \mathrm{constant} \mathrm{room}$ temperature of $21 \pm 2^{\circ} \mathrm{C}$; behavioral testing was performed during the light cycle between 10:00 A.M. and 2:00 P.M. Procedures were conducted in accordance with the National Institutes of Health Guide for the Care and Use of Laboratory Animals as approved by the Animal Care and Use Committee of the Facultad de Ciencias Químicas, Universidad Nacional de Córdoba; efforts were made to minimize animal suffering and to reduce the number of animals used.

In all experiments, rats were habituated to the manipulation, namely, transporting them to an experimental room, removing them from their cages, handling, weighing, and returning them to their home cages. These procedures were repeated twice a day during 1 week before the experiments.

Stressor. Rats were transferred in their own home cages to an experimental room and placed for $30 \mathrm{~min}$ in a plastic restrainer fitted closely to body size (inner diameter, $6 \mathrm{~cm}$ ) and drilled with numerous holes to allow accessibility of fresh air, with only the tail and the tip of the nose free (Cancela et al., 1988). At the end of the stress session, rats were returned to the colony room. No other subjects were present in the experimental room during stress exposure. Control animals were transferred in their own home cages to the experimental room, gently handled for $\sim 2 \mathrm{~min}$ each, and then returned to the colony room.

Conditioning apparatus. In experiments designed to evaluate contextual fear learning, conditioning chambers, placed in acoustically isolated separate rooms maintained at a constant temperature of $21 \pm 2^{\circ} \mathrm{C}$, were used. These chambers were different in location, size, color, illumination, floor, and walls. The first chamber, referred to as the paired context, was made of gray acrylic $(20 \times 23 \times 20 \mathrm{~cm})$ with a clear lid. The grid floor consisted of 10 parallel stainless-steel grid bars, each measuring $4 \mathrm{~mm}$ in diameter and spaced $1.5 \mathrm{~cm}$ apart (center to center), and was connected to a scrambled shocker (Ugo Basile, Comerio, Italy). Illumination was provided by a $2.5 \mathrm{~W}$ white light bulb. Background noise was supplied by ventilation fans and shock scramblers. The second chamber, designated as the unpaired context, was made of wood $(33 \times 25 \times 33 \mathrm{~cm})$ with a lid of transparent plastic, black walls, and a black rubber floor. This procedure was meant to keep the unpaired context as different as possible from the one originally used during training (paired context) and therefore maximize the possibility of obtaining different levels of expression of the acquired memory. Obviously, differences in the expression of learning in the present circumstances might be attributable to contextual changes and/or changes regarding discrete stimuli that define the context. Both chambers (paired and unpaired) were cleaned with $70 \%$ aqueous ethanol solution before and after each session.

Contextual fear conditioning. The procedure used was similar to that described previously (Isoardi et al., 2004). On the day of conditioning, rats were transported from the housing room and individually placed in the paired context. Animals were left undisturbed for a 3 min acclimation period (preshock period), followed by three unsignaled scrambled foot- shocks ( $0.7 \mathrm{~mA} ; 3 \mathrm{~s}$ duration; 30 s intershock interval). Animals remained in the chamber for an additional 2 min (postshock period); immediately after, they were brought back to their home cages and returned to the colony room.

Testing for contextual fear conditioning was performed $24 \mathrm{~h}$ after training. Rats were randomly assigned to two subgroups: one-half of the animals were reintroduced in the paired context for a $10 \mathrm{~min}$ period (without shocks), and the other one-half were exposed for the same period of time to the unpaired context.

The behavior of each rat was continuously videotaped to score freezing behavior during the 3 min preshock period, during the 2 min postshock period, and during the entire $10 \mathrm{~min}$ testing period (two consecutive periods of $5 \mathrm{~min}$ ), either in the paired or in the unpaired context. Freezing behavior was scored at the end of the experiment by a person who was blind with regard to the experimental condition of each animal. The total time spent freezing in each period was quantified (in seconds) using a stopwatch and expressed as the percentage of total time. Freezing, a commonly used index of fear in rats, was defined as a total absence of body or head movement except that associated with breathing (Blanchard and Blanchard, 1969; Bolles and Collier, 1976).

Implantation of guide cannulas for intracerebral infusions. Animals were anesthetized with an intraperitoneal injection of chloral hydrate $(400$ $\mathrm{mg} / \mathrm{kg}$ ) and placed into a stereotaxic instrument (Stoelting, Wood Dale, IL) with the incisor bar set at $-3.3 \mathrm{~mm}$. The scalp was incised and retracted, and small burr holes $(2 \mathrm{~mm}$ diameter) were drilled into the skull using a dental drill. Two stainless-steel guide cannulas (22 gauge; length, $12 \mathrm{~mm}$ ) were stereotaxically lowered into the BLA using the following coordinates: anterior, $-2.8 \mathrm{~mm}$; lateral, $\pm 5.0 \mathrm{~mm}$; ventral, -6.1 ; or into the CeA using the following coordinates: anterior, -2.2 ; lateral, \pm 4.5 ; ventral, -5.5 according to the atlas of Paxinos and Watson (1997). The guide cannulas were secured in place using acrylic cement and two 4 $\mathrm{mm}$ stainless-steel screws anchored to the skull. Stainless dummy cannulas protruding $0.5 \mathrm{~mm}$ beyond the tips were placed inside the guide cannulas to prevent occlusion. Animals were removed from the stereotaxic instrument and recovered under a heat lamp and close supervision. After surgery, animals were gently handled every day, replacing missing dummy cannulas when necessary. The behavioral tests commenced $6 \mathrm{~d}$ after surgery.

To perform local infusions into the different amygdala nuclei, rats were hand-restrained, and the dummy cannulas were removed from the guide cannulas and replaced by infusion cannulas (30 gauge). Infusion cannulas fitted into and extended $2.5 \mathrm{~mm}$ beyond the guide cannulas. The infusion cannulas were connected, via polyethylene tubing (PE 10; Becton Dickinson, Sparks, MD), to $10 \mu \mathrm{l}$ microsyringes (Hamilton, Reno, NV) mounted on a microinfusion pump (Harvard Apparatus, Holliston, MA). Each rat was injected with $0.5 \mu \mathrm{l} /$ side at a flow rate of 0.5 $\mu \mathrm{l} / \mathrm{min}$. This volume was selected according to the size and structure of these nuclei. Moreover, this amount corresponds to the standard volumes used in the literature for local infusions in the BLA with different drugs (Wilensky et al., 2000; Rodrigues et al., 2001), including BMI (Dickinson-Anson and McGaugh, 1997). To allow diffusion of the drug, the infusion cannulas were kept in place for another minute before being replaced with the dummy cannulas.

Electrophysiology. The procedure used was similar to that described previously (Isoardi et al., 2004). Animals were killed by decapitation and their brains were quickly removed and placed in ice-cold $\left(-3^{\circ} \mathrm{C}\right)$ oxygenated artificial CSF (ACSF) consisting of the following (in mM): 124 $\mathrm{NaCl}, 2.60 \mathrm{KCl}, 1.25 \mathrm{KH}_{2} \mathrm{PO}_{4}, 2 \mathrm{Mg}_{2} \mathrm{SO}_{4}, 26 \mathrm{NaHCO}_{3}, 2 \mathrm{CaCl}_{2}$, and 10 glucose, bubbled with a $95 \% \mathrm{O}_{2} / 5 \% \mathrm{CO}_{2}$ mixture and adjusted to a final $\mathrm{pH}$ of 7.36-7.4 with $1 \mathrm{~N} \mathrm{NaOH}$. Working on an ice block, the brain was divided sagittally, $2 \mathrm{~mm}$ from the midsagittal plane, and laid on the sagittal face created by this cut. An oblique cut parallel to the olfactory bundle was made behind the temporal lobe. This cutting plane was adopted to increase the preservation of incoming fibers from the cortex, which arrive at the BLA following a descending oblique path (De Olmos et al., 1985; Fisk and Wyss, 2000). Laying on the surface created by this cut, the anterior part of the brain was glued with cyanoacrylate to the cutting block of a Vibratome (Ted Pella, Redding, CA). Oblique frontal slices containing the BLA and external capsule (EC) were cut at a thick- 
A

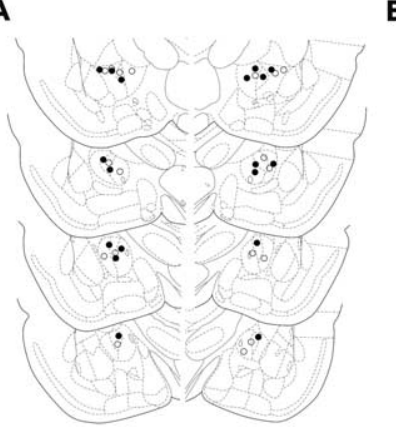

B

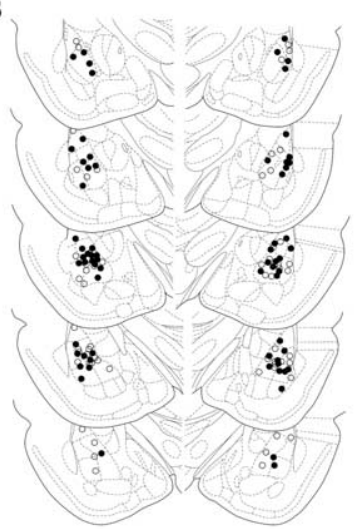

C

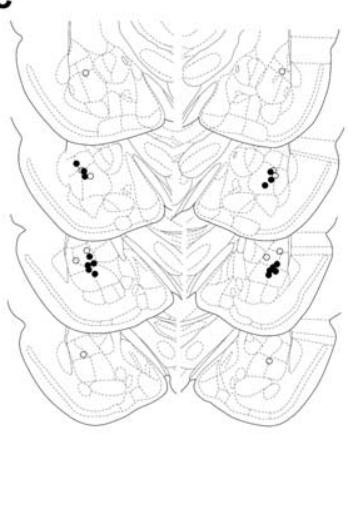

Figure 1. Placement of infusion cannulas. Schematic drawings of coronal sections show the location of the cannulas in $\mathrm{Ce}(\mathrm{O}$, $\mathrm{SAL} ; \boldsymbol{O}, \mathrm{BMI})(\boldsymbol{A})$, the BLA $(\bigcirc, \mathrm{SAL} ; \boldsymbol{\Theta}, \mathrm{BMI})(\boldsymbol{B})$, and the $\mathrm{BLA}(\mathrm{O}, \mathrm{VEH} ; \boldsymbol{O}, \mathrm{MDZ})(\boldsymbol{C})$. The drawings were adapted from Paxinos and Watson (1997).

ness of $400 \mu \mathrm{m}$. The slices were stored for $1 \mathrm{~h}$ in oxygenated ACSF maintained at room temperature. For recording, slices were transferred to a chamber continuously perfused with oxygenated ACSF $(2 \mathrm{ml} / \mathrm{min})$ maintained at $30 \pm 1{ }^{\circ} \mathrm{C}$. Visual control through a stereoscopic microscope allowed placement of a recording electrode in the BLA and a stimulating electrode in the EC. The recording electrode was a glass pipette filled with $2 \%$ Pontamine Sky Blue in $2 \mathrm{M} \mathrm{NaCl}(0.5-2 \mathrm{M} \Omega)$ connected to a differential AC amplifier (WPI, Sarasota, FL). The output was monitored on a digital oscilloscope (Nicolet Technologies, Madison, WI) and sampled at a rate of $2 \mathrm{kHz}$ with a TL-1/DMA interface board for storage on the hard disk of a PC-type computer using pCLAMP software (Molecular Devices, Union City, CA) for experimental control, data acquisition, and analysis. The stimulation electrode was constructed of PtIr wire, $50 \mu \mathrm{m}$ in diameter, isolated with Teflon (WPI), except for the cut ends. Stimulation consisted of monophasic square pulses $(0.2 \mathrm{~ms}$ at 0.06 $\mathrm{Hz}$ ) delivered by a pulse generator with constant-current isolation unit (Grass, West Warwick, RI). To evaluate the response of BLA neurons to cortical input, graded stimulus intensities were used; 16 records were obtained for each stimulus intensity and averaged off-line. The amplitude of the evoked population spike (PS) was measured as the distance from the maximal negative peak of the PS to a line tangent to the lower and upper shoulders (see Fig. 4A). At least four stimulus intensities $(0.2-7 \mathrm{~mA})$ were used in every case, covering the range from threshold to supramaximal intensity; the results were used to plot input/output (I/O) curves for the amplitude of the PS. The magnitude of inhibition was assessed by comparing the height of PSs generated by double-pulse stimulation to the EC. The interval between double pulses (20, 40, 60, $100 \mathrm{~ms})$ was adopted to fall within the time course of the intracellularly recorded IPSP attributed to activation of GABAergic interneurons (Rainnie et al., 1991b). In these experiments, intensity of stimulation was chosen to evoke a response corresponding to $50 \%$ of maximal. The change in amplitude of the response to the second stimulus was normalized to the amplitude of the first response taken to represent $100 \%$. PSs were counted by visual inspection of individual records obtained at maximal stimulation, and the numbers were averaged for each case. To induce LTP, a single train of $1 \mathrm{~s}$ duration of $0.2 \mathrm{~ms}$ pulses at $100 \mathrm{~Hz}$ was administered, selecting the stimulation intensity that evoked $50 \%$ of maximum PS response. To evaluate the potentiation, recordings were repeated 10 , $20,40,60,80$, and $100 \mathrm{~min}$ after high-frequency stimulation (HFS). For each slice, the raw data for the PS amplitude was transformed into percentage of the basal records obtained before HFS; only one slice was studied per rat. For statistical purposes, percentages were normalized by logarithmic transformation and compared using ANOVA followed by Tukey's honest significant difference post hoc test. Drugs were applied to the slice by switching the bath superfusate from normal ACSF to ACSF containing $2 \mu \mathrm{M}$ diazepam (DZM) (Roche, Welwyn Garden City, UK), $50 \mu \mathrm{M}$ picrotoxin (PTX), or $30 \mu \mathrm{M}$ BMI.

Histological procedures. After behavioral tests, rats were killed by an overdose of chloral hydrate, and their brains were removed and immersion-fixed in a $4 \%$ formalin solution. Frontal sections were cut in a cryostat (Leica, Nussloch, Germany), the injection sites were localized, and the extent of tissue damage caused by cannulation was examined under a light microscope. The injection sites were drawn on plates taken from a rat brain atlas (Paxinos and Watson, 1997). Only animals with proper cannula placements and tissue damage not exceeding the diameter of the cannulas were included in the study (Fig. 1).

Drugs. BMI was dissolved and diluted in $0.9 \%$ sodium chloride (SAL) immediately before use. It was administered bilaterally at a dose of $10 \mathrm{pmol}$ in a volume of $0.5 \mu \mathrm{l}$. The dose of BMI selected is well below doses that have been found previously to induce convulsion and brain seizure activity (Turski et al., 1985; Sanders and Shekhar, 1991; Dickinson-Anson and McGaugh, 1997). MDZ (Gobbi Novag, Buenos Aires, Argentina) was diluted in distilled water [vehicle (VEH)] and given intraperitoneally at the dose of 0.5 $\mathrm{mg} / \mathrm{kg}, 20 \mathrm{~min}$ before either restraint exposure or intra-amygdaloid injection of BMI. A dose of $1 \mu \mathrm{g} / 0.5 \mu \mathrm{l} \mathrm{MDZ}$ was used for BLA administration 10 min before restraint. MDZ is a potent, fast-acting benzodiazepine whose half-life is relatively short. Except where noted, all drugs were obtained from Sigma-Aldrich (St. Louis, MO).

Experiment 1: effect of restraint on contextual fear conditioning: influence of midazolam pretreatment. This experiment was designed to examine the behavior performed in the contextual fear-conditioning paradigm by rats subjected to a previous restraint session, with or without systemic or BLA administration of MDZ before the stressful experience.

Eighty rats were randomly assigned to two groups: control (CON) and restraint (RES). One-half of the animals of each group was injected intraperitoneally with MDZ $(0.5 \mathrm{mg} / \mathrm{kg})$ and one-half with the VEH $(1.0$ $\mathrm{ml} / \mathrm{kg})$, resulting in the following four groups: VEH-CON $(n=20)$, MDZ-CON $(n=20)$, VEH-RES $(n=20)$, and MDZ-RES $(n=20)$. Twenty minutes after injection, RES animals were immobilized as described before. CON animals were returned to their home cages and left undisturbed. Twenty-four hours later, all subjects were trained and tested in either the paired or unpaired context, as described previously.

Fourteen rats were subjected to the cannula implantation procedure into the BLA. Six days later, animals were transported to the experimental room and allowed $30 \mathrm{~min}$ to acclimate. Rats were randomly assigned to two groups: VEH-RES $(n=6)$ and MDZ-RES $(n=8)$. Bilateral VEH MDZ injections were made into the BLA $10 \mathrm{~min}$ before the restraint session. Twenty-four hours later, all subjects were trained and tested in the paired context, as described previously.

An additional experiment was performed to study whether the effect of restraint after conditioning affects fear memory expression. Sixteen animals were randomly assigned to two groups: CON and RES. Twenty-four hours after training, RES animals were immobilized as described before. CON animals remained in their home cages without any manipulation. Twenty-four hours later, all subjects were tested in the paired context.

Experiment 2: effect of local infusion with BMI into the BLA or into the $C e A$ on contextual fear conditioning: influence of MDZ pretreatment. These experiments were designed to evaluate the behavior performed in the contextual fear-conditioning paradigm by rats previously submitted to local administrations of BMI into the BLA or into the CeA.

Sixty-five rats were subjected to the cannula implantation procedure. Six days later, animals were transported to the experimental room and allowed $30 \mathrm{~min}$ to acclimate. One-half of the animals of each group were injected with MDZ (0.5 mg/kg, i.p.) and one-half with VEH $(1.0 \mathrm{ml} / \mathrm{kg}$, i.p.). Twenty minutes later, animals received, into the BLA, a microinjection of either BMI or SAL, resulting in the following four groups: VEHSAL $(n=16)$, MDZ-SAL $(n=16)$, VEH-BMI $(n=17)$, and MDZ-BMI $(n=16)$. After microinjection, animals were returned to their home 

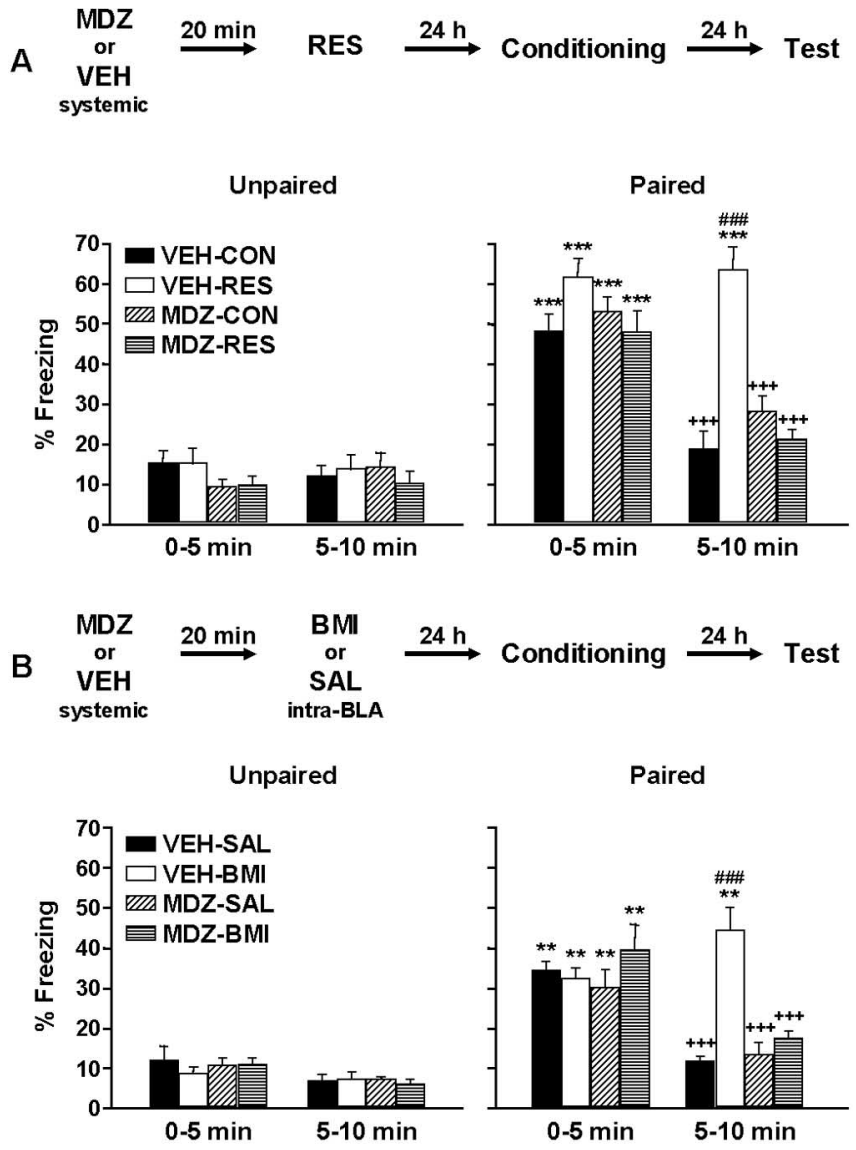

Figure 2. Effect of restraint or BMl into the BLA on contextual fear conditioning: influence of systemic MDZ pretreatment. Freezing behavior was evaluated in the paired context or in a novel, unpaired context. Values represent the mean \pm SEM percentage of time spent freezing during the two 5 min test periods. $A$, Freezing response exhibited by control or stressed animals with or without MDZ pretreatment ( $n=10$ per group). $\boldsymbol{B}$, Freezing response exhibited by SALor BMI-treated animals with or without MDZ pretreatment ( $n=8$ per group). ${ }^{* * *}$ Significantly different from the respective unpaired group $(p<0.001) .{ }^{+++}$Significantly different from

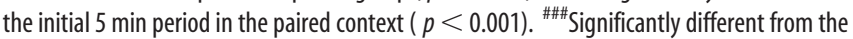
other groups in the second 5 min period in the paired context $(p<0.001)$. ${ }^{*}$ Significantly different from the respective unpaired group $(p<0.01)$.

cages and left without any additional manipulation. The following day, all subjects were examined in the contextual fear-conditioning paradigm as described previously.

In an additional experiment, 18 rats were implanted with cannulas into the CeA. Six days later, animals were transported to the experimental room. Thirty minutes later, animals received a microinjection of either $\operatorname{BMI}(n=9)$ or SAL $(n=9)$. After microinjection, animals were returned to their home cages and left without any additional manipulation. Twenty-four hours later, all subjects were trained and tested in the paired context, as described previously.

Experiment 3: effects of restraint on evoked potentials and LTP in the BLA: influence of midazolam pretreatment. These experiments were designed to test the hypothesis that restraint stress would modify BLA neuron excitability and plasticity in response to cortical afferent stimulation. One week before being killed, all animals were habituated to the manipulation that preceded killing, namely, removing them from their cages, placing them in the guillotine for $5 \mathrm{~s}$, and returning them to their home cages (twice a day). Rats were randomly assigned to four groups: CON and RES with MDZ or VEH pretreatment. Twenty minutes after injection, RES animals were immobilized as described before. After injection, CON animals were returned to their home cages and left without any additional manipulation. The following day, animals were used for electrophysiological experiments.

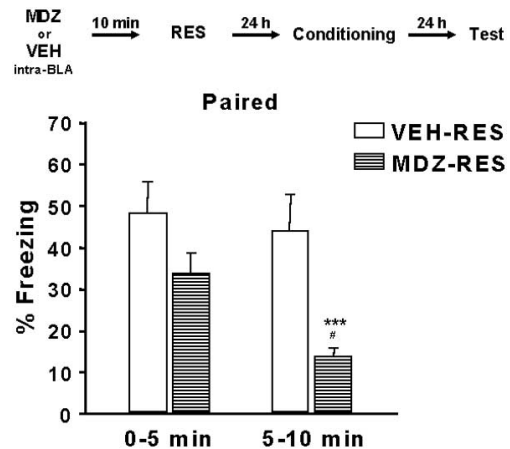

Figure 3. Effect of $M D Z$ injection into the BLA on the influence of restraint on contextual fear conditioning. Freezing behavior was evaluated in the paired context. Values represent the mean \pm SEM percentage of time spent freezing during the two 5 min test periods $(n=6-8)$. ***Significantly different from the initial 5 min period $(p<0.001)$. "Significantly different from the VEH-RES group in the second 5 min period $(p<0.05)$.

\section{Results}

Experiment 1: effect of restraint on contextual fear conditioning: influence of midazolam pretreatment

To evaluate whether previous stress affects subsequent fear conditioning, we studied freezing behavior in previously restrained animals. To further analyze the possibility that $\mathrm{GABA}_{\mathrm{A}}$ receptor modulation was involved, animals were subjected to systemic or local BLA MDZ pretreatment. Figure $2 \mathrm{~A}$ depicts freezing behavior, evaluated $24 \mathrm{~h}$ after training, in animals systemically injected with MDZ or VEH. As expected, during the first $5 \mathrm{~min}$ period, animals tested in paired conditions displayed more time in freezing than animals tested in unpaired conditions. In addition, freezing varied over the $10 \mathrm{~min}$ test. ANOVA showed a significant effect of MDZ pretreatment $\left(F_{(1,72)}=9.25 ; p=0.003281\right)$, RES treatment $\left(F_{(1,72)}=6.07 ; p=0.016148\right)$, test condition $\left(F_{(1,72)}=\right.$ $180.06 ; p<0.000001)$, time $\left(F_{(1,72)}=44.87 ; p<0.000001\right)$, and MDZ pretreatment by RES treatment by test condition by time interaction $\left(F_{(1,72)}=5.19 ; p=0.025673\right)$. Furthermore, Newman-Keuls post hoc tests revealed a significant difference between paired and unpaired conditions in both CON and RES groups $(p<0.001)$ during the first $5 \mathrm{~min}$ period. In animals exposed to the paired context, a significant increase in freezing was evident in the initial $5 \mathrm{~min}$ period, compared with the second $5 \mathrm{~min}$ period in VEH-CON, MDZ-CON, and MDZ-RES groups $(p<$ $0.001)$. Moreover, in the second $5 \mathrm{~min}$ period, VEH-RES animals showed significantly more freezing behavior compared with the other groups $(p<0.001)$. Notably, MDZ pretreatment prevented the facilitating influence of stress on the conditioned freezing response. In contrast, in the unpaired condition, no significant differences among the different experimental groups were observed.

Analysis of time spent freezing during the preshock or postshock periods revealed no significant differences among the different experimental groups. The means \pm SEM for the preshock period were $10.92 \pm 2.09 \%$ for VEH-CON, $8.92 \pm 2.87 \%$ for VEH-RES, $4.11 \pm 0.91 \%$ for MDZ-CON, and $7.25 \pm 2.31 \%$ for MDZ-RES groups. The means \pm SEM for the postshock period were $68.29 \pm 4.43 \%$ for VEH-CON, $68.17 \pm 5.10 \%$ for VEHRES, $68.58 \pm 5.00 \%$ for MDZ-CON, and $61.00 \pm 6.20 \%$ for MDZ-RES groups.

Figure 3 shows the effect of MDZ administration in the BLA 10 min before stress. ANOVA showed a significant effect of MDZ pretreatment $\left(F_{(1,12)}=8.03 ; p=0.0151\right)$, time $\left(F_{(1,12)}=21.14\right.$; $p=0.0006)$, and MDZ pretreatment by time interaction 
$\left(F_{(1,12)}=9.14 ; p=0.0106\right)$. Furthermore, Newman-Keuls post hoc tests revealed a significant increase in freezing in the initial 5 min period compared with the second 5 min period in the MDZRES group $(p<0.001)$. A significant difference between MDZRES and VEH-RES groups $(p<0.05)$ was evident during the second 5 min period.

In the experiment designed to test the effect of restraint on memory expression, we observed a significant increase in freezing during the initial $5 \mathrm{~min}$ period compared with the second 5 min period in both CON and RES groups. ANOVA showed a significant effect of time $\left(F_{(1,14)}=56.46 ; p=0.000003\right)$. During the first 5 min period, the means \pm SEM for the CON and RES groups were $53.96 \pm 4.59$ and $61.38 \pm 4.86 \%$, respectively. During the second $5 \mathrm{~min}$ period, the equivalent scores were $26.21 \pm$ 2.37 and $24.54 \pm 1.69 \%$, respectively. No significant differences were observed in freezing scores between CON and RES groups at any time.

Three main results emerge from the present experiments: (1) a previous and brief restraint session facilitates fear conditioning; (2) systemic or local MDZ pretreatment prevents the facilitating influence of previous stress on fear conditioning; and (3) postconditioning stress does not affect memory expression.

\section{Experiment 2: effect of local infusion with BMI into the BLA or into the CeA on contextual fear conditioning: influence of MDZ pretreatment}

To evaluate the role of $\mathrm{GABA}_{\mathrm{A}}$ receptors in the BLA on fear conditioning, the effect of local BMI microinjection on fear conditioning was studied in animals with or without MDZ pretreatment. Results are shown in Figure $2 B$. As expected, animals tested in the associated context spent more time in freezing than animals tested in the nonassociated context. In addition, freezing varied over the $10 \mathrm{~min}$ test. ANOVA showed a significant effect of BMI treatment $\left(F_{(1,57)}=7.79 ; p=0.007135\right)$, test condition $\left(F_{(1,57)}=110.15 ; p<0.000001\right)$, time $\left(F_{(1,57)}=38.73 ; p<\right.$ $0.000001)$, and MDZ pretreatment by BMI treatment by test condition by time interaction $\left(F_{(1,57)}=11.63 ; p=0.001198\right)$. Furthermore, during the first 5 min period, the Newman-Keuls post $h o c$ test revealed significant differences between paired and unpaired conditions in both the SAL- and BMI-treated groups $(p<$ $0.01)$. When tested in the paired context, rats from VEH-SAL, MDZ-SAL, and MDZ-BMI groups showed more freezing during the first compared with the second 5 min test session $(p<0.001)$. In addition, during the second $5 \mathrm{~min}$ period, the VEH-BMI group exhibited significantly more freezing $(p<0.001)$ than the other groups when tested in the associated context. As expected, MDZ pretreatment prevented the facilitating influence of BMI on the conditioned freezing response. Similar freezing behavior was observed during the first and the second 5 min periods by animals from all of the experimental groups when tested in the unpaired context.

Analysis of time spent freezing during the preshock or postshock period revealed no significant differences between the experimental groups. The means \pm SEM for the preshock period were $3.65 \pm 0.60 \%$ for VEH-SAL, $4.61 \pm 1.20 \%$ for VEH-BMI, $2.81 \pm 0.77 \%$ for MDZ-SAL, and $3.65 \pm 0.80 \%$ for MDZ-BMI groups. The means \pm SEM for the postshock period were $40.31 \pm 6.45 \mathrm{~s}$ for $\mathrm{VEH}-\mathrm{SAL}, 43.38 \pm 4.81 \mathrm{~s}$ for VEH-BMI, $35.57 \pm 3.60 \mathrm{~s}$ for MDZ-SAL, and $29.38 \pm 3.61 \mathrm{~s}$ for MDZ-BMI groups.

Freezing behavior in the paired context of animals subjected to BMI microinjection into the CeA was comparable with that exhibited by animals injected with SAL, indicating that BMI in-
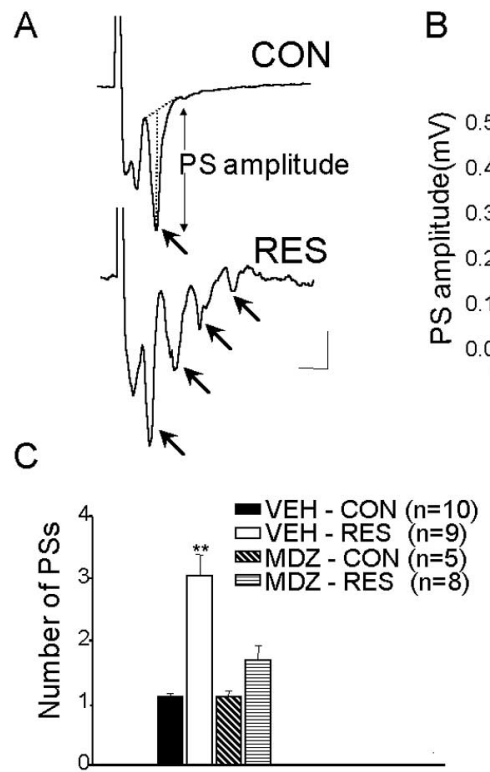

B

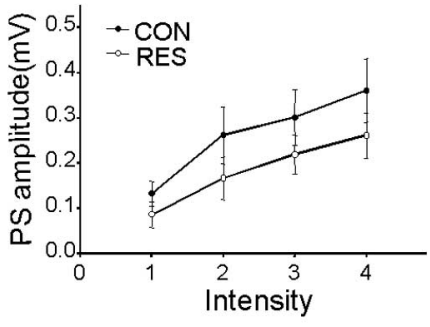

D

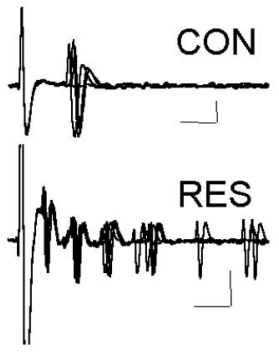

Figure 4. Comparison of responses evoked in the BLA by stimuli applied to the EC in slices from control and stressed animals. A, Examples of field potentials (average of 16 sweeps). In CON rats (top), EC stimulation evoked a single PS (arrow), whereas in RES rats (bottom), the same stimulus evoked multiple PSs (arrows). $\boldsymbol{B}$, Amplitude of PS as a function of stimulus intensity. No significant differences were obtained. C, Mean \pm SEM number of PSs recorded in slices from CON and RES rats with MDZ or VEH pretreatment (number of animals in parentheses). ${ }^{* *}$ Significantly different from control $(p<0.01)$. $\boldsymbol{D}$, Examples of single-unit responses evoked in CON (top) and RES (bottom) rats; note multiple responses in the latter. Calibration: $\boldsymbol{A}$, $0.2 \mathrm{mV}, 5 \mathrm{~ms} ; \boldsymbol{D}, 0.1 \mathrm{mV}, 5 \mathrm{~ms}$.

fusion into the CeA did not affect fear conditioning. Freezing behavior varied in both groups over the $10 \mathrm{~min}$ test. The means \pm SEM were $38.15 \pm 4.73$ and $18.48 \pm 3.03 \%$ for the SAL group, and $31.00 \pm 1.34$ and $12.48 \pm 3.69 \%$ for the BMI group, in the first and second 5 min tests, respectively. ANOVA showed a significant effect of time $\left(F_{(1,16)}=64.53 ; p<0.000001\right)$. There is no significant effect of BMI treatment by time interaction $\left(F_{(1,16)}=\right.$ $0.001 ; p=0.976146)$. Furthermore, the Newman-Keuls post hoc test revealed a significant reduction of freezing in the second compared with the first 5 min period in both groups $(p<0.001)$. Analysis of time spent freezing during the preshock or postshock period revealed no significant differences among the experimental groups. The means \pm SEM for the preshock period were $2.22 \pm 0.96 \%$ for SAL and $4.07 \pm 1.40 \%$ for BMI groups. The means \pm SEM for the postshock period were $46.67 \pm 7.11 \%$ for SAL and $42.69 \pm 4.78 \%$ for BMI groups.

The results of these experiments show the following: (1) blockade of $\mathrm{GABA}_{\mathrm{A}}$ receptors in only the BLA facilitates subsequent fear conditioning, and (2) MDZ pretreatment attenuates the selective facilitating influence of $\mathrm{GABA}_{\mathrm{A}}$ receptor blockade in the BLA on fear conditioning.

Experiment 3: effects of restraint on evoked potentials and LTP in the BLA: influence of midazolam pretreatment

The characteristics of the potentials evoked in the BLA by EC stimulation in vivo and in slices have been described and analyzed in detail previously (Isoardi et al., 2004). To evaluate the possibility that previous stress could affect neuronal excitability in the BLA, evoked potentials and synaptic plasticity were studied in four groups of rats: VEH-CON, VEH-RES, MDZ-CON, and MDZ-RES. As shown in Figure $4 A$, the dominant feature of the 
response in slices from VEH-CON rats is the presence of a PS (arrow) generated by the synchronous firing of basolateral projecting (pyramidal) neurons. Latency to peak for the PS was $8 \pm$ $0.2 \mathrm{~ms}$; no differences were seen in the latency of the primary PS between VEH-CON and VEH-RES rats ( $t$ test; $p=0.14$ ). Comparison of I/O curves for both groups yielded similar results $\left(F_{(1,14)}=0.5 ; p=0.5\right)$ (Fig. $\left.4 B\right)$. However, in slices from VEHRES rats, a single stimulus evoked a response containing multiple PSs (Fig. 4A). The three to four additional PSs occurred at $4 \mathrm{~ms}$ intervals and were of decreasing amplitude. In MDZ-RES rats, the responses were not different from MDZ-CON or VEH-CON (Fig. 4C). Figure $4 C$ shows that the number of PSs was significantly different for the four groups (one-way ANOVA; $F_{(3,28)}=$ 15.94; $p<0.00001)$; the mean number of PSs in VEH-RES rats was significantly $(p<0.001)$ larger than in VEH-CON (3.04 \pm 0.35 and $1.1 \pm 0.05$, respectively). Occasionally, single units could be recorded, and, as expected, in control slices, firing latencies for single-action potentials coincided with the PS (Fig. 4D); multiple firings were not observed even with the highest stimulus intensities. However, in slices from restrained rats, multiple (five to six) firings were observed in single-unit records (Fig. $4 \mathrm{D}$ ). These results suggested the possibility that inhibitory mechanisms that normally restrict repetitive firing in the BLA (Wang et al., 2001, 2002) were affected in restrained animals. To investigate this possibility, $\mathrm{GABA}_{\mathrm{A}}$ receptor antagonists (BMI and PTX) were applied to normal slices and a positive modulator of GABAergic transmission (DZM) was applied to slices from restrained rats. In control slices $(n=4)$, after $10-15$ min of perfusion with PTX, multiple PSs were observed in response to single stimuli (basal, $1.15 \pm 0.15$ PSs; after PTX, $3.1 \pm 0.3$ PSs; $p<0.001$; Tukey's post hoc) (Fig. 5A). Perfusion with PTX had no effect on the already high number of PSs in slices from restrained rats $(n=4)$. Perfusion with BMI also increased the number of PSs recorded from control slices $(n=4)$ (basal, $1 \pm 0.0$ PSs; after BMI, $2.7 \pm 0.24 ; p=0.006$; $t$ test).

Potentiation of GABAergic transmission by perfusion with DZM suppressed the repetitive response in slices from restrained rats $(n=4)$ so that single PSs were evoked by EC stimulation (basal, $2.9 \pm 0.26$ PSs; after DZM, $1.2 \pm 0.07$ PSs; $p<0.001$; Tukey's post hoc) (Fig. $5 \mathrm{~B}$ ). Perfusion with DZM had no effect on the number of PSs in slices from control rats $(n=4)$. No significant differences in the amplitude of the primary response were observed between basal and drug-treated slices.

Paired-pulse stimulation represents a tool for analysis of the excitation-inhibition cycle in neuronal networks, including the amygdala (Wang et al., 2002; Isoardi et al., 2004). Short interstimulus interval-dependent paired-pulse inhibition (PPI) is considered to depend on an IPSP that is $\mathrm{GABA}_{\mathrm{A}}$ mediated (Delaney and Sah, 2001; Braga et al., 2002). Taking into account the results just described, we used PPI to evaluate the GABAergic inhibitory activity in basolateral neurons, with the prospect of defining differences between control and stressed animals. In restrained animals $(n=7)$, only one rat showed inhibition, whereas six cases showed facilitation; the mean for the entire group was $155 \pm 27 \%$ (Fig. 6). Multivariate ANOVA indicated a statistically significant effect associated with pretreatment $\left(F_{(1,12)}=4.75 ; p=\right.$ $0.04)$. Post hoc analysis indicated significant differences $(p<$ 0.001 ; Tukey's post hoc) with $20 \mathrm{~ms}$ of interstimulus interval. This lack of PPI in stressed animals may be attributable to a decrease of the GABA-dependent IPSP that occurs simultaneously or after the EPSP evoked by EC stimulation (Rainnie et al., 1991a,b; Chapman and Bellavance, 1992; Wang et al., 2001). Interestingly,
A

B
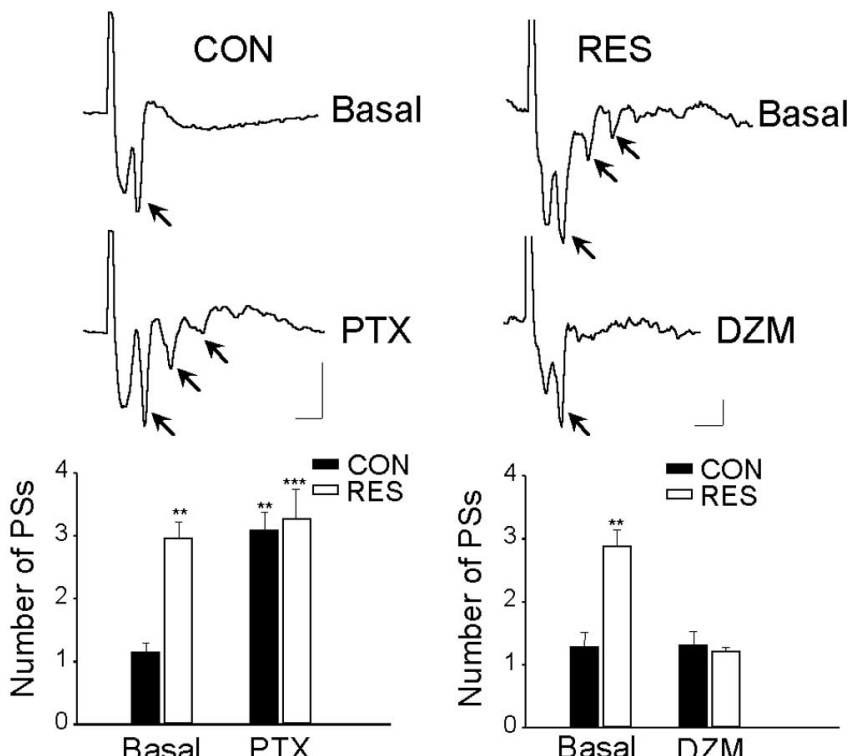

Figure 5. Effect of PTX or DZM perfusion on the response evoked in the BLA by EC stimulation. $\boldsymbol{A}$, Representative single traces before (top) and after (bottom) perfusion with $50 \mu \mathrm{M}$ PTX in a slice from a control rat (arrows indicate PSs). The bar graph shows the mean number of PSs \pm SEM recorded from CON $(n=4)$ and RES $(n=4)$ rats before and after perfusion with 50 $\mu \mathrm{M}$ PTX. ${ }^{* *}$ Significantly different from basal values in control rats $(p<0.01)$. ${ }^{* * *}$ Significantly different from basal values in control rats $(p<0.001)$. $\boldsymbol{B}$, Representative single traces before (top) and after (bottom) perfusion with $2 \mu \mathrm{M}$ DZM in a slice from a restrained rat (arrows indicates PSs). The bar graph shows the mean number of PSs \pm SEM recorded from CON ( $n=$ 4) and RES $(n=4)$ rats before and after perfusion with $2 \mu \mathrm{m}$ DZM. ${ }^{* *}$ Significantly different from all other groups $(p<0.01)$. Calibration: $0.1 \mathrm{mV}, 5 \mathrm{~ms}$.

although the PS was not smaller in the response to the second stimulus, the secondary repetitive spikes were suppressed (Fig. 6), suggesting that some measure of inhibitory control is still operative in these animals.

As previously reported ( $\mathrm{Li}$ et al., 1998; Isoardi et al., 2004), a single train of HFS in the EC did not induce significant longlasting potentiation of the PS amplitude in the BLA of VEH-CON rats $(n=8)$ (Fig. 7$)$. However, the same pattern of stimulation induced LTP in slices from VEH-RES rats $\left(n=7 ; F_{(3,24)}=4.94\right.$; $p<0.01$ ) (Fig. 7). Ten minutes after HFS, the amplitude of the PS had doubled in six of seven cases, remaining potentiated for the duration of the experiments ( $p<0.05$; Tukey's post hoc) at least 100 min after HFS. The importance of GABAergic transmission in this effect was investigated by pretreatment of the animals with MDZ. In MDZ-RES animals $(n=8)$, the increase in plasticity resulting from exposure to inescapable stress was prevented ( $p<$ 0.05; Tukey's post hoc) (Fig. 7). Treatment of control animals with MDZ (MDZ-CON; $n=5$ ) had no effect on LTP induction (Fig. 7). These data suggest that stress results in increased excitability of pyramidal neurons, which, in turn, facilitates the induction of LTP. This increased excitability is probably attributable to suppression of GABAergic inhibition (disinhibition), because MDZ pretreatment prevents both increased excitability and induction of LTP.

\section{Discussion}

The present data confirm previous findings (Shors and Mathew, 1998; Fischer et al., 2002; Cordero et al., 2003), showing that a brief threatening experience facilitated the subsequent formation of a new fear memory. This enhanced fear memory is expressed 

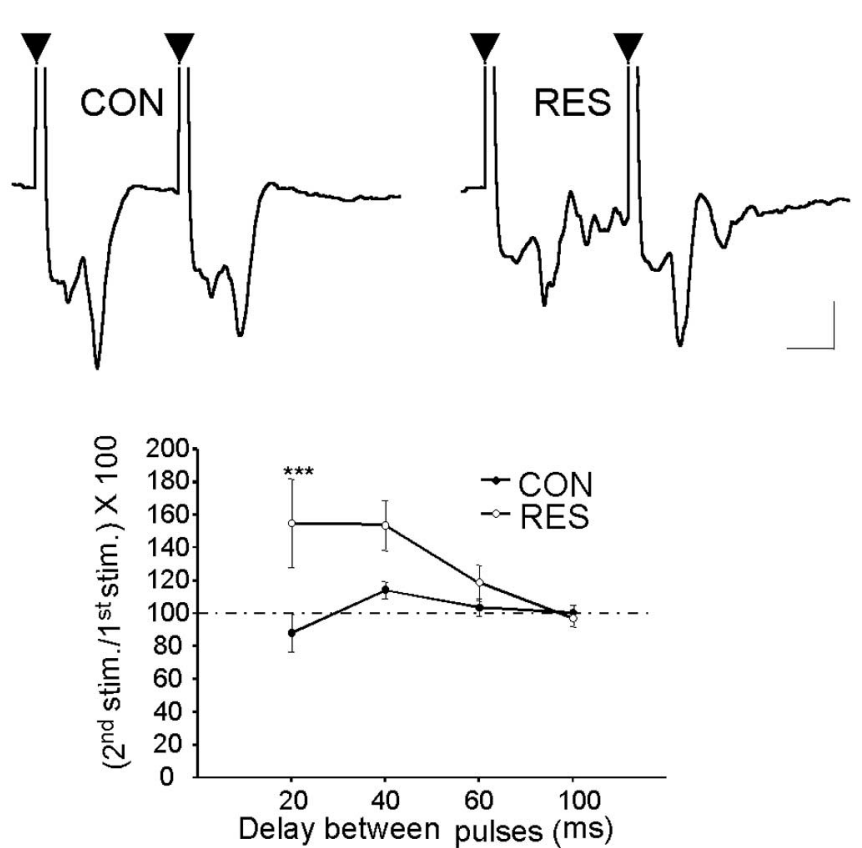

Figure 6. Paired-pulse inhibition of evoked potentials in the BLA of control and restrained rats. Data are means \pm SEM of the percentage amplitude of the response to the second stimulus with respect to response to the first stimulus. The inset shows representative records obtained in slices from CON $(n=7)$ and RES $(n=7)$ rats using an interstimulus interval of $20 \mathrm{~ms}$. Each trace is the average of 16 sweeps. Arrowheads indicate the first and second stimuli. ***Significantly different from control ( $p<0.001$ ). Calibration: $0.5 \mathrm{mV}, 5 \mathrm{~ms}$.

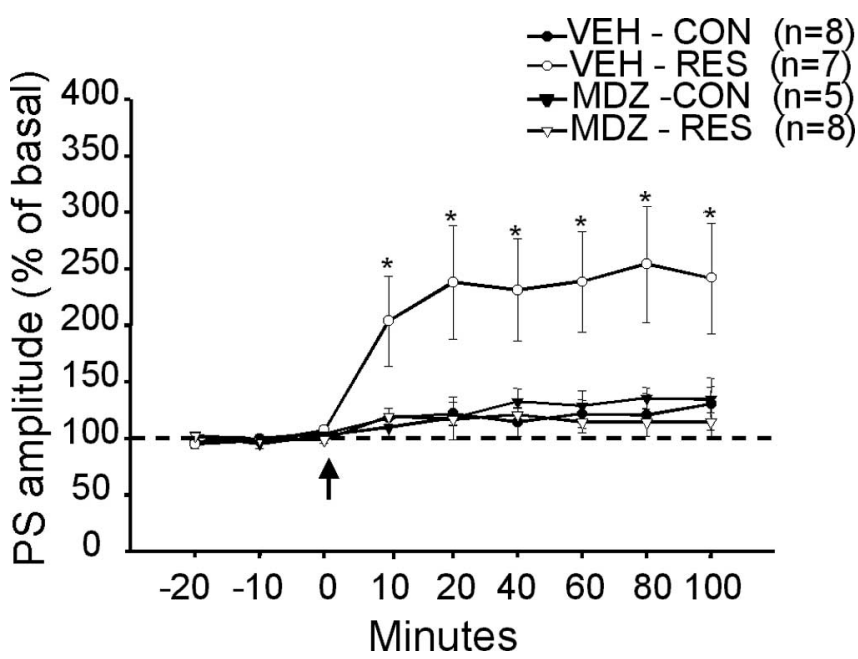

Figure 7. LTP in the BLA: effect of pretreatment with MDZ. PS amplitude is expressed as the percentage of basal records obtained in the same slice before HFS (arrow). The values are means \pm SEM for slices obtained from control and restrained rats pretreated with MDZ or VEH (number of animals in parentheses). * Significantly different from all other records at each time after HFS ( $p<0.05$ or smaller). Dotted line indicates $100 \%$.

only when stressed animals are exposed to the paired context, indicating that this response is sustained by associative learning. In fact, comparable amounts of freezing were obtained in control and stressed animals when exposed to the nonassociated context, suggesting that the facilitating effect was not related to sensitization or to the enhancement of an unspecific fear response. The facilitating influence on conditioned freezing shown by stressed animals was observed during the second $5 \mathrm{~min}$ period of the test. Considering that continued exposure to the associated context could initiate extinction learning (Myers and Davis, 2002), the increased freezing behavior of stressed animals could be attributable to an attenuation of the extinction process rather than enhanced fear acquisition. However, it is important to keep in mind that resistance to extinction could reflect the strength of the acquisition process (Myers and Davis, 2002). Additional experiments are necessary to elucidate this possibility. Finally, our data indicate that the facilitating influence of stress on learned fear is attributable to an effect on the formation and not on the expression of a new fear memory.

The current findings also showed that local or systemic pretreatment with MDZ prevented facilitation of fear conditioning resulting from previous stress. Also, the effect of BMI infusion in the BLA was prevented by systemic MDZ. These effects suggest that reduced inhibitory neurotransmission in the BLA is involved in the enhancement of conditioned fear. In support of this possibility are the reports that conditioned fear stimulus decreased extracellular GABA levels in the amygdala (Stork et al., 2002). In addition, stressful stimuli reduced stimulated chloride uptake mediated by the $\mathrm{GABA}_{\mathrm{A}}$ receptor complex in the amygdala (Martijena et al., 1997), as well as benzodiazepine binding, and the expression of $\alpha 1 \mathrm{GABA}_{\mathrm{A}}$ receptor mRNA in the BLA (Liu and Glowa, 2000). Also, blockade of benzodiazepine sites or lesions of the BLA attenuate the anxiolytic influence of systemic benzodiazepines (Sanders and Shekhar, 1991). Furthermore, Goosens and Maren (2002) suggested that the BLA is able to retain aspects of fear memories even in the absence of the CeA. Shors and Mathew (1998) demonstrated a selective role of the BLA in the facilitating influence of stress on classical eyeblink conditioning. Finally, numerous findings indicated that drugs affecting aversively motivated memory are effective only when administered into the BLA (Roozendaal and McGaugh, 1997; Roozendaal et al., 2002). Confirming the site specificity of GABAergic function, present findings show that local infusion of BMI into only the BLA induced a facilitating influence on fear conditioning similar to that induced by stress.

Stress, by reducing GABAergic feedforward and/or recurrent inhibition, could result in an enhanced excitability in the BLA. The present electrophysiological findings are consistent with this hypothesis, because multiple PSs were evoked in response to EC stimulation only in animals previously restrained, and perfusion of the slices with DZM normalized the evoked response. Coincidentally, pretreatment with MDZ attenuated both the facilitating influence of stress on fear memory and synaptic excitability in the

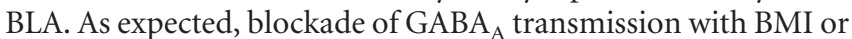
PTX induced repetitive firing in slices from normal rats. Once again, behavioral data correspond with these findings, because fear conditioning was strongly facilitated by blockade of $\mathrm{GABA}_{\mathrm{A}}$ receptors in the BLA.

Slices from restrained rats showed significant paired-pulse facilitation instead of inhibition, as would be expected if the IPSPs generated by activation of inhibitory interneurons (Rosenkranz and Grace, 1999, 2002) were reduced or suppressed. The fact that I/O curves did not show synaptic potentiation as a consequence of stress appears contradictory with this interpretation. However, if the effects of stress occurred exclusively or predominantly on recurrent inhibitory circuits, this would result in repeated firing to a single stimulus without potentiation of the primary response. Coincidentally, although perfusion of control slices with PTX induced the appearance of repetitive PSs, the amplitude of the primary response did not change. Also, perfusion with DZM suppressed multiple spikes in restrained rats without changing the amplitude of the primary response. Together, these results indi- 
cate that by altering the equilibrium between excitation and inhibition, exposure to stress results in an attenuated inhibitory control of BLA projection neurons, favoring multiple firing in response to cortical afferent activity.

Recently, Rainnie et al. (2004) showed that repeated microinjections of a CRF agonist (urocortin) into the BLA caused a longlasting reduction of both spontaneous and induced GABAmediated IPSPs and increased duration of EPSPs. This would result in increased probability of firing and repeated action potentials, as we find in restrained animals. Interestingly, urocortin induced anxiety-like responses in behavioral tests, and immobilization augmented CRF concentration (Merlo et al., 1995) in the amygdala. Although a single injection of urocortin did not result in long-lasting changes of excitability, the contribution of CRF released in the amygdala during stress should be taken into account when considering the possible mechanisms responsible for the disinhibition we observed. Also, stress severely impairs the facilitating influence of norepinephrine acting via $\alpha 1$ sites on GABAergic inhibition in the BLA (Braga et al., 2004). Based on all of this evidence, it seems appropriate to ask by what mechanism an isolated stressful experience induced such long-lasting changes in GABA transmission in the BLA. Among the many mechanisms that could affect presynaptic or postsynaptic function, the possibility of autoinhibition of GABA release resulting from intense stimulation (Davies et al., 1991) is particularly attractive. It is well known that exposure to a stressful event results in intense activation of fear-processing circuits, in which the BLA is inserted (Hamann et al., 1999). Recent work from Lüthi's laboratory (Bissiere et al., 2003; Loretan et al., 2004) has shown that in the mouse lateral amygdala dopamine can suppress GABAergic feedforward inhibition; they propose this as a cellular mechanism for the modulation of synaptic plasticity (LTP) and fear conditioning.

The emotional state generated by stress can act as a filter to determine which information is retained and the accuracy with which that retention occurs. The observed increase in fear conditioning should be sustained by corresponding changes in plasticity in the amygdala, responsible for fear learning and memory (LeDoux, 2000); LTP should reflect similar changes. This prediction was confirmed by our experiments; in restrained rats, LTP was generated by a stimulation paradigm that was insufficient in control animals. It has been shown that, although the excitatory drive into BLA neurons primarily results from activation of AMPA receptors, the NMDA receptors can also be activated at the resting membrane potential of these neurons (Gean and Chang, 1991; Rainnie et al., 1991a; Li et al., 1995). However, the NMDA receptor-mediated excitation temporally overlaps with the inhibitory input, which rapidly curtails the EPSP. If GABAergic inhibition is reduced, the NMDA receptor-mediated EPSP should be unmasked, leading to long-term changes in synaptic plasticity and facilitation of memory formation. The resulting increased plasticity in the corticoamygdaloid input of stressed rats nicely explains the observed increase in fear memory. It has been reported that platform stress also facilitates induction of LTP in the entorhinal cortex-basal amygdaloid nucleus pathway in vivo (Vouimba et al., 2004). Although the exact relationship between cortex and BLA and their respective roles during fear conditioning are still a matter of debate (LeDoux, 2000; Richter-Levin, 2004), there is no doubt that both are essential for the acquisition of appropriate responses to fearful stimuli.

Stress-related hormones are potent regulators of LTP in the hippocampus (Diamond et al., 1992, 2004; Maroun and Richter-
Levin, 2003). However, available data indicate that the hippocampus and amygdala could respond differently to stress (Vouimba et al., 2004). Although it is known that stress-related hormones are crucially implicated in the memory-modulating role of the BLA (McGaugh, 2004), we are not aware of studies investigating the effect of stress-related hormones on LTP in the amygdala.

Present behavioral and neurophysiological findings are strikingly similar to those observed after DZM withdrawal in rats (Isoardi et al., 2004). In this condition, we demonstrated increased fear learning, multiple BLA responses to cortical stimulation (both in vivo and in vitro), and facilitation of LTP induction. Moreover, compatible experimental data sustained our hypothesis that the behavioral and neurophysiological consequences of withdrawal or stress could be explained by the depression of GABAergic inhibition in the BLA. Together, these results suggest that the reduction of GABAergic inhibitory control in the BLA may be a common mechanism that is necessary and sufficient to generate a heightened emotional state.

The facilitating influence of previous stressors on the promotion of new aversive memories could have a major adaptive role, improving survival chances in the face of future threats (Maren, 2001; Wiedenmayer, 2004). Depending on the emotional history of the organism, GABAergic transmission in the BLA would serve as a dynamic gating mechanism, adjusting the behavioral output to changing environmental demands. Moreover, alterations of such a mechanism could result in the occurrence of exaggerated emotional and dysfunctional states, including the formation of traumatic memories.

\section{References}

Beylin AV, Shors TJ (1998) Stress enhances excitatory trace eyeblink conditioning and opposes acquisition of inhibitory conditioning. Behav Neurosci 112:1327-1338.

Biggio G, Concas A, Corda MG, Giorgi O, Sanna E, Serra M (1990) GABAergic and dopaminergic transmission in the rat cerebral cortex: effect of stress, anxiolytic and anxiogenic drugs. Pharmacol Ther 48:121-142.

Bissiere S, Humeau Y, Lüthi A (2003) Dopamine gates LTP induction in lateral amygdala by suppressing feedforward inhibition. Nat Neurosci 6:587-592.

Blair HT, Schafe GE, Bauer EP, Rodrigues SM, LeDoux JE (2001) Synaptic plasticity in the lateral amygdala: a cellular hypothesis of fear conditioning. Learn Mem 8:229-242.

Blanchard RJ, Blanchard DC (1969) Crouching as an index of fear. J Comp Physiol Psychol 67:370-375.

Bolles RC, Collier AC (1976) Effect of predictive cues on freezing in rats. Anim Learn Behav 4:6-8.

Braga MF, Aroniadou-Anderjaska V, Post RM, Li H (2002) Lamotrigine reduces spontaneous and evoked $\mathrm{GABA}_{\mathrm{A}}$ receptor-mediated synaptic transmission in the basolateral amygdala: implications for its effects in seizure and affective disorders. Neuropharmacology 42:522-529.

Braga MF, Aroniadou-Anderjaska V, Manion ST, Hough CJ, Li H (2004) Stress impairs alpha(1A) adrenoceptor-mediated noradrenergic facilitation of GABAergic transmission in the basolateral amygdala. Neuropsychopharmacology 29:45-58.

Cancela LM, Volosin M, Molina VA (1988) Chronic stress attenuation of alpha 2-adrenoceptor reactivity is reversed by naltrexone. Pharmacol Biochem Behav 31:33-35.

Cancela LM, Bregonzio C, Molina VA (1995) Anxiolytic-like effect induced by chronic stress is reversed by naloxone pretreatment. Brain Res Bull 36:209-213.

Chapman PF, Bellavance LL (1992) Induction of long-term potentiation in the basolateral amygdala does not depend on NMDA receptor activation. Synapse 11:310-318.

Cole BJ, Hillmann M, Seidelmann D, Klewer M, Jones GH (1995) Effects of 
benzodiazepine receptor partial inverse agonists in the elevated plus maze test of anxiety in the rat. Psychopharmacology (Berl) 121:118-126.

Cordero MI, Venero C, Kruyt ND, Sandi C (2003) Prior exposure to a single stress session facilitates subsequent contextual fear conditioning in rats. Evidence for a role of corticosterone. Horm Behav 44:338-345.

Davies CH, Starkey SJ, Pozza MF, Collingridge GL (1991) GABA autoreceptors regulate the induction of LTP. Nature 349:609-611.

Delaney AJ, Sah P (2001) Pathway-specific targeting of $\mathrm{GABA}_{\mathrm{A}}$ receptor subtypes to somatic and dendritic synapses in the central amygdala. J Neurophysiol 86:717-723.

De Olmos JS, Alheid GF, Beltramino C (1985) Amygdala. In: The rat nervous system (Paxinos G, ed), pp 223-334. Sydney: Academic.

Diamond DM, Bennett MC, Fleshner M, Rose GM (1992) Inverted-U relationship between the level of peripheral corticosterone and the magnitude of hippocampal primed burst potentiation. Hippocampus 2:421-430.

Diamond DM, Park CR, Woodson JC (2004) Stress generates emotional memories and retrograde amnesia by inducing an endogenous form of hippocampal LTP. Hippocampus 14:281-291.

Dickinson-Anson H, McGaugh JL (1997) Bicuculline administered into the amygdala after training blocks benzodiazepine-induced amnesia. Brain Res 752:197-202.

Fanselow MS, Kim JJ (1992) The benzodiazepine inverse agonist DMCM as an unconditional stimulus for fear-induced analgesia: implications for the role of $\mathrm{GABA}_{\mathrm{A}}$ receptors in fear-related behavior. Behav Neurosci 106:336-344

Fischer A, Sananbenesi F, Schrick C, Spiess J, Radulovic J (2002) Cyclindependent kinase 5 is required for associative learning. J Neurosci 22:3700-3707.

Fisk GD, Wyss JM (2000) Descending projections of infralimbic cortex that mediate stimulation-evoked changes in arterial pressure. Brain Res 859:83-95.

Gean PW, Chang FC (1991) Bursting discharges in disinhibited amygdala slices: the role of excitatory amino acid receptors. Neuropharmacology 30:797-802.

Goosens KA, Maren S (2002) Long-term potentiation as a substrate for memory: evidence from studies of amygdaloid plasticity and pavlovian fear conditioning. Hippocampus 12:592-599.

Hamann SB, Ely TD, Grafton ST, Kilts CD (1999) Amygdala activity related to enhanced memory for pleasant and aversive stimuli. Nat Neurosci 2:289-293.

Isoardi NA, Martijena ID, Carrer HF, Molina VA (2004) Increased fear learning coincides with neuronal dysinhibition and facilitated LTP in the basolateral amygdala following benzodiazepine withdrawal in rats. Neuropsychopharmacology 29:1852-1864.

Jasnow AM, Huhman KL (2001) Activation of $\mathrm{GABA}_{\mathrm{A}}$ receptors in the amygdala blocks the acquisition and expression of conditioned defeat in Syrian hamsters. Brain Res 920:142-150.

LeDoux JE (1993) Emotional memory: in search of systems and synapses. Ann NY Acad Sci 702:149-157.

LeDoux JE (2000) Emotion circuits in the brain. Annu Rev Neurosci 23:155-184.

Li H, Weiss SRB, Chuang DM, Post RM, Rogawski MA (1998) Bidirectional synaptic plasticity in the rat basolateral amygdala: characterization of an activity-dependent switch sensitive to the presynaptic metabotropic glutamate receptor antagonist $2 S$ - $\alpha$-ethylglutamic acid. J Neurosci $18: 1662-1670$.

Li XF, Phillips R, LeDoux JE (1995) NMDA and non-NMDA receptors contribute to synaptic transmission between the medial geniculate body and the lateral nucleus of the amygdala. Exp Brain Res 105:87-100.

Liu M, Glowa JR (2000) Regulation of benzodiazepine receptor binding and $\mathrm{GABA}_{\mathrm{A}}$ subunit mRNA expression by punishment and acute alprazolam administration. Brain Res 887:23-33.

Loretan K, Bissiere S, Lüthi A (2004) Dopaminergic modulation of spontaneous inhibitory network activity in the lateral amygdala. Neuropharmacology 47:631-639.

Maren S (2001) Neurobiology of pavlovian fear conditioning. Annu Rev Neurosci 24:897-931.

Maroun M, Richter-Levin G (2003) Exposure to acute stress blocks the induction of long-term potentiation of the amygdala-prefrontal cortex pathway in vivo. J Neurosci 23:4406-4409.

Martijena ID, Calvo N, Volosin M, Molina VA (1997) Prior exposure to a brief restraint session facilitates the occurrence of fear in response to a conflict situation: behavioral and neurochemical correlates. Brain Res 752:136-142.

Martijena ID, Rodríguez Manzanares PA, Lacerra C, Molina VA (2002) GABAergic modulation of the stress response in frontal cortex and amygdala. Synapse 45:86-94.

McGaugh JL (2004) The amygdala modulates the consolidation of memories of emotionally arousing experiences. Annu Rev Neurosci 27:1-28.

McGaugh JL, McIntyre CK, Power AE (2002) Amygdala modulation of memory consolidation: interaction with other brain systems. Neurobiol Learn Mem 78:539-552.

Merlo PE, Lorang M, Yeganeh M, Rodriguez, DF, Raber J, Koob GF, Weiss F (1995) Increase of extracellular corticotropin-releasing factor-like immunoreactivity levels in the amygdala of awake rats during restraint stress and ethanol withdrawal as measured by microdialysis. J Neurosci 15:5439-5447.

Millan MJ (2003) The neurobiology and control of anxious states. Prog Neurobiol 70:83-244.

Muller J, Corodimas KP, Fridel Z, LeDoux JE (1997) Functional inactivation of the lateral and basal nuclei of the amygdala by muscimol infusion prevents fear conditioning to an explicit conditioned stimulus and to contextual stimuli. Behav Neurosci 111:683-691.

Myers KM, Davis M (2002) Behavioral and neural analysis of extinction. Neuron 36:567-584

Niehoff DL, Kuhar MJ (1983) Benzodiazepine receptors: localization in rat amygdala. J Neurosci 3:2091-2097.

Paxinos G, Watson C (1997) The rat brain in stereotaxic coordinates, Ed 3, pp 15-31. San Diego: Academic.

Petersen EN, Braestrup C, Scheel-Kruger J (1985) Evidence that the anticonflict effect of midazolam in amygdala is mediated by the specific benzodiazepine receptors. Neurosci Lett 53:285-288.

Rainnie DG, Asprodini EK, Shinnick-Gallagher P (1991a) Excitatory transmission in the basolateral amygdala. J Neurophysiol 66:986-998.

Rainnie DG, Asprodini EK, Shinnick-Gallagher P (1991b) Inhibitory transmission in the basolateral amygdala. J Neurophysiol 66:999-1009.

Rainnie DG, Bergeron R, Sajdyk TJ, Patil M, Gehlert DR, Shekhar A (2004) Corticotrophin releasing factor-induced synaptic plasticity in the amygdala translates stress into emotional disorders. J Neurosci 24:3471-3479.

Richter-Levin G (2004) The amygdala, the hippocampus, and emotional modulation of memory. Neuroscientist 10:31-39.

Rodrigues SM, Schafe GE, LeDoux JE (2001) Intra-amygdala blockade of the NR2B subunit of the NMDA receptor disrupts the acquisition but not the expression of fear conditioning. J Neurosci 21:6889-6896.

Roozendaal B, McGaugh JL (1997) Glucocorticoid receptor agonist and antagonist administration into the basolateral but not central amygdala modulates memory storage. Neurobiol Learn Mem 67:176-179.

Roozendaal B, Brunson KL, Holloway BL, McGaugh JL, Baram TZ (2002) Involvement of stress-released corticotropin-releasing hormone in the basolateral amygdala in regulating memory consolidation. Proc Natl Acad Sci USA 99:13908-13913.

Rosenkranz JA, Grace AA (1999) Modulation of basolateral amygdala neuronal firing and afferent drive by dopamine receptor activation in vivo. J Neurosci 19:11027-11039.

Rosenkranz JA, Grace AA (2002) Cellular mechanisms of infralimbic and prelimbic prefrontal cortical inhibition and dopaminergic modulation of basolateral amygdala neurons in vivo. J Neurosci 22:324-337.

Sanders SK, Shekhar A (1991) Blockade of GABA ${ }_{\mathrm{A}}$ receptors in the region of the anterior basolateral amygdala of rats elicits increases in heart rate and blood pressure. Brain Res 567:101-110.

Scheel-Kruger J, Petersen EN (1982) Anticonflict effect of the benzodiazepines mediated by a GABAergic mechanism in the amygdala. Eur J Pharmacol 82:115-116.

Shors TJ (2001) Acute stress rapidly and persistently enhances memory formation in the male rat. Neurobiol Learn Mem 75:10-29.

Shors TJ, Mathew PR (1998) NMDA receptor antagonism in the lateral/ basolateral but not central nucleus of the amygdala prevents the induction of facilitated learning in response to stress. Learn Mem 5:220-230.

Shors TJ, Weiss C, Thompson RF (1992) Stress-induced facilitation of classical conditioning. Science 257:537-539.

Stork O, Ji FY, Obata K (2002) Reduction of extracellular GABA in the mouse amygdala during and following confrontation with a conditioned fear stimulus. Neurosci Lett 327:138-142. 
Takagi M, Yamamato C (1981) The long-lasting inhibition recorded in vitro from the lateral nucleus of the amygdala. Brain Res 206:474-478.

Turski WA, Cavalheiro EA, Calderazzo-Filho LS, Kleinrok Z (1985) Injections of picrotoxin and bicuculline into the amygdaloid complex of the rat: an electroencephalographic behavioural and morphological analysis. Neuroscience 14:37-54.

Vouimba RM, Yaniv D, Diamond D, Richter L (2004) Effects of inescapable stress on LTP in the amygdala versus the dentate gyrus of freely behaving rats. Eur J Neurosci 19:1887-1894.

Wang C, Wilson WA, Moore SD (2001) Role of NMDA, non-NMDA, and GABA receptors in signal propagation in the amygdala formation. J Neurophysiol 86:1422-1429.

Wang C, Kang P, Wilson WA, Moore SD (2002) Properties of the pathways from the lateral amygdala nucleus to basolateral nucleus and amygdalostriatal transition area. J Neurophysiol 87:2593-2601.

Washburn MS, Moises HC (1992a) Electrophysiological and morphological properties of rat basolateral amygdaloid neurons in vitro. J Neurosci 12:4066-4079.

Washburn MS, Moises HC (1992b) Inhibitory responses of rat basolateral amygdaloid neurons recorded in vitro. Neuroscience 50:811-830.

Wiedenmayer CP (2004) Adaptations or pathologies? Long-term changes in brain and behavior after a single exposure to severe threat. Neurosci Biobehav Rev 28:1-12.

Wilensky AE, Schafe GE, LeDoux JE (2000) The amygdala modulates memory consolidation of fear-motivated inhibitory avoidance learning but not classical fear conditioning. J Neurosci 20:7059-7066. 